\title{
Understanding Dispositional Hope in general and clinical populations
}

\author{
Espinoza, M. ${ }^{1,2}$, Molinari, G. ${ }^{1,2}$, Etchemendy, E. ${ }^{2,3}$, Herrero, R. ${ }^{1,2}$, Botella, C. ${ }^{1,2,3}$ \& Baños, \\ R.M. ${ }^{2,3,4}$ \\ ${ }^{1}$ University Jaume I; ${ }^{2}$ PROMOSAM Excellence in Research Program (PSI2014-56303-REDT) MINECO; \\ ${ }^{3}$ CIBERObn ISCI III; ${ }^{4}$ University of Valencia.
}

\begin{abstract}
Introduction Hope is a positive, future-thinking construct that is highly related to pursuing and achieving our personal goals. Considering its relevance for well-being and psychological adjustment, the purpose of this study is to explore the psychometric properties of the Spanish version of the Dispositional Hope Scale (DHS) (Snyder et al., 1991), its relation with important psychological health indicators (depression, hopelessness, optimism, general self-efficacy and quality of life), and examine the possible differences between clinical (CP) and general populations (GP).

Method Sample was composed of 290 volunteers. Measures of hopelessness, depression, optimism, quality of life, self-efficacy, and positive-negative affect were administered. Hope was assessed again 1 month later to collect test-retest data.

Results CFA supports the unidimensional structure. In addition, good internal consistency and test-retest values were found. Further, based on the one-factor model, results revealed that the Spanish DHS has strong factorial invariance across populations (GP and CP). The differences in the hope levels detected between CP and GP appear to be mainly associated with positive affect and depressive symptoms.
\end{abstract}


Conclusions Results broaden the existing data about the Spanish DHS and support its usefulness not only for research, but also for clinical purposes.

Keywords: Hope, Spanish validation, CFA, factorial invariance, clinical population

\section{Introduction}

Hope is an important variable in the pursuit and achievement of our goals. Hope means having the will and determination to accomplish our goals, and it also implies having the ability to use multiple strategies to reach them. According to Snyder, Irving and Anderson (1991), hope is a positive motivational state consisting of two distinct ways of thinking about our goals: Pathways thinking (the perception of personal abilities to generate routes to desired goals), and Agency thinking (the perception of one's ability to initiate and continue the use of these routes). These two ways of thinking reinforce each other during the goal attainment process (Snyder et al., 2002). According to this definition, desired goals are a key element of hope and a cognitive component that anchors the hope theory (Snyder et al., 2002).

The concept of hope has been related to various benefits, and several studies have found a

positive association between hope and well-being (Alarcon, Bowling \& Khazon, 2013; Magaletta \& Oliver, 1999), life satisfaction, meaning in life (Feldman \& Snyder, 2005), psychological adjustment (Chang \& DeSimone, 2001; Moraitou, Kolovou, Papasozomenou \& Paschoula, 2006), coping with illness (Affleck \& Tennen, 1996; Snyder, Lehman, Kluck \& Monsson, 2006; Stanton, Danoff-Burg \& Huggins, 2002; Berendes et al., 2010; Kortte et al., 2012), and therapeutic improvement (Irving et al., 2004).

Snyder et al. (1991) developed both a theory of hope and a measurement instrument, the "Dispositional Hope Scale" (DHS), which has been highly employed in research, mainly as a 
measure of positive future thinking. This scale assesses dispositional hope, with the understanding that hope is not a goal-related state objectively defined by external sources, but rather an enduring disposition subjectively defined by people's perceptions about their life goals and goal-related capabilities (Snyder et al., 1991). Based on their theory, the authors proposed a higher-order, two-factor model for this scale: agency and pathways (Snyder et al., 1991; Babyak, Snyder \& Yoshinobu, 1993). This scale has been translated and validated in different countries and with various types of samples (Abdel-Khalek \& Snyder, 2007; Chen, Shen \& Li, 2009; Gana, Daigre \& Ledrich, 2013; Kato \& Snyder, 2005; Marques, Lopez, Fontaine, Coimbra \& Mitchell, 2014; Shehni-Yailagh et al., 2012; Sun, Ng \& Wang, 2012; Creamer et al., 2009; Roesch \& Vaughn, 2006; Vernberg, Snyder \& Schuh, 2005). In all cases, the two-factor structure proposed by Snyder et al (1991) was confirmed and showed convergent validity with other variables (self-esteem, optimism, self-efficacy, satisfaction with life, distress, hopelessness, depression, anxiety, among others). Moreover, the reliability generalization of the internal consistency and test-retest values of the DHS was analyzed, obtaining support for its reliability scores (Hellmann, Pittman \& Munoz, 2013).

Despite the extensive support found for the two-factor model, some authors have proposed a unidimensional model for this hope scale. Brouwer, Meijer, Weekers and Baneke (2008) argued that all items measure the same construct, a general hope factor, and recently, Galiana, Oliver, Sancho and Tomas (2014) also proposed a mono-factorial model for the DHS in a Spanish population.

Galiana et al (2014) published the first presentation and validation of a Spanish version of the DHS, offering evidence of adequate psychometric properties. Their study assessed DHS dimensionality, internal consistency and nomological validity with life satisfaction and 
spirituality measures. However, this study was conducted only with Spanish university students and does not present evidence of the stability of the scale. Therefore, the aims of the present study are: a) to assess the factorial structure of the Spanish version of the scale (bidimensional or unidimensional) in general and clinical populations; b) to analyze the factorial invariance of the scale between clinical and general populations; c) to examine the possible differences in hope between clinical and general populations; d) to assess the relationships between hope and depression, hopelessness, optimism, general self-efficacy and quality of life; and e) to analyze the internal consistency and test-retest reliability of the Spanish version of the DHS.

\section{Methods}

\subsection{Participants}

The total sample was composed of 290 Spanish-speaking volunteers (249 women, 41 men), 168 participants from the general population (GP) and 122 from a clinical population (CP) (see Table 1 for demographic characteristics). GP were recruited through online platforms, and CP were individuals seeking treatment for psychological disorders $(n=22)$ or emotional problems related to medical conditions $(\mathrm{n}=100)$. CP were recruited from the Psychological Assistance Service at the university and from an online patient platform.

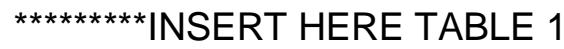

\subsection{Translation of the Adult Dispositional Hope Scale (DHS)}

Given that this study began before Galiana et al (2014) was published, a Spanish translation of the scale was carried out. First, a native Spanish speaker with a high level of English who was 
aware of the objective of the study translated the DHS into Spanish. Then, a native English speaker who had a fluent level of Spanish, but was not familiar with the DHS, performed a backtranslation from Spanish to English. Any discrepancies between the Spanish and English translators were resolved by agreement. The Spanish version was judged to be an accurate translation of the original English version. When our Spanish DHS version was compared to the Galiana et al. version of the scale, some differences in wording were detected. However, all items refer to the same content and intention. Only item \#12 shows a slight deviation from the Galiana et al. version (difference in the verb tense used).

\subsection{Measures}

Dispositional Hope Scale (DHS, Snyder et al., 1991): This is a self-report inventory composed of 12 items $($ Agency $=4$ items; Pathways $=4$ items; Fillers $=4$ items $)$, with an 8-point Likert-type response scale ranging from 1 (definitely false) to 8 (definitely true).

Beck Depression Inventory II (BDI-II, Beck, Steer \& Brown, 1996, Spanish validation by Sanz, Navarro \& Vázquez, 2003): This is one of the most widely-used self-report instruments to assess depression. This inventory includes 21 items that evaluate cognitive, behavioral, affective and somatic symptoms of depression during the past two weeks. In the current sample, Cronbach's $\alpha$ was .96.

Beck Hopelessness Scale (BHS, Beck et al., 1974; Spanish version, Aguilar et al. 1995): This is a 20-item self-report inventory that reflects the respondent's negative expectations. The response format is dichotomous; each item is either true or false in describing the respondent's attitude during the past week. To control for acquiescence, 9 items are keyed false, and 11 are keyed true. 
The scale has demonstrated acceptable psychometric properties. In the current sample, internal consistency coefficients were high, Cronbach's alpha, $\alpha=.82$

General Self Efficacy Scale-12 (GSES-12, Bosscher, Smit \& Kempen, 1997; Spanish version, Herrero et al., 2014): This is a 12-item scale that evaluates perceived global self-efficacy and three main aspects of it: initiative, persistence and effort. All items are responded to on a 5-point scale, ranging from 1 (never happens to me) to 5 (always happens to me). This inventory has shown good psychometric properties (Woodruff \& Cashman, 1993). In the current sample, Cronbach's $\alpha$ for the total scale was .82. The Initiative subscale has an $\alpha=.73$, Effort has an $\alpha$ $=.76$, and Persistence has an $\alpha=.78$.

Positive And Negative Affect Schedule (PANAS, Watson, Clark \& Tellegen, 1988): It includes 20 items that evaluate positive (10 items) and negative (10 items) affect on a 5-point scale. Respondents indicate, in general, how they usually feel. Cronbach's $\alpha$ were: .89 for positive affect and .87 for negative affect.

Life Orientation Test-revised (LOT-R, Sheier, Carver \& Bridges, 1994; Spanish version: Perczek, Carver, Price \& Pozo-Kaderman, 2000): This is the most widely-used self-report instrument to assess individual differences in generalized optimism (general future expectations), and it includes 10 items (4 fillers) with a 5-point response scale. Cronbach's $\alpha$ was .67.

Quality of Life Index (QLI-Sp, Spanish version, Mezzich, Ruiperez, Pérez, Yoon \& Mahmud, 2000): It consists of 10 items that evaluate physical, psychological and emotional well-being, as well as social and occupational functioning, including an overall perception of quality of life. This scale assesses quality of life at the present. All items are responded to on a 10-point scale. The index presents good psychometric properties. Cronbach's $\alpha$ was .92 


\subsection{Procedure}

Participants were informed that the study was voluntary and confidential, and they signed a consent form stating their willingness to participate. No particular inclusion or exclusion criteria were established, and no incentive was offered for participation. Data were collected from 2009 to 2013 for both the GP and CP samples.

The GP subsample was recruited online. A link to the study was published in different forums and public social networks. Participants in the CP subsample filled out all the instruments individually in an assessment session. Two scales were not assessed in the entire sample: hopelessness was only assessed in GP and self-efficacy was only evaluated in CP. Participants were contacted 1 month after the first administration of the DHS and asked to complete it again, in order to collect data on the test-retest reliability.

\subsection{Data analysis}

Confirmatory Factor Analysis (CFA) was performed to test previous models found in the literature, using the Mplus program, version 7. The missing data were treated with the Expectation Maximization Algorithm method (using SPSS 17.0). The following recommended goodness-of-fit indices were used: a corrected Satorra-Bentler chi-square (S-B $\chi 2$ ), the Comparative Fit Index (CFI), the Standardized Root Mean Squared Residuals (SRMR) and the Root Mean Squared Error of Approximation (RMSEA). The following criteria were used to indicate the fit of the CFA models to the data: $\mathrm{CFI} \geq 0.90$, SRMR $\leq 0.08$ and RMSEA $\leq 0.06$ (Hu \& Bentler, 1999). Besides, to compare the models, S-B Chi-Square differences were took into account. 
Factorial invariance across groups (GP and CP) was calculated. Specifically, configural, metric, scalar and strict measurement invariance were estimated through multi-sample analyses. Descriptive statistics of the total score for the DHS were calculated for the GP and CP. Internal consistency of the Spanish DHS was assessed using Cronbach's and split-half coefficients. In addition, the temporal stability of the data and the discriminant and convergent validity were also calculated using correlation coefficient analysis. Criterion validity of the Spanish DHS was examined by calculating its correlation with measures of depression, self-efficacy, positive and negative affect, optimism, hopelessness and quality of life.

\section{Results}

\subsection{Confirmatory factor analysis}

CFA was used to test the 4 competing models: a model with a mono-factorial structure (model 1), a model with 2 correlated first-order factors (model 2), a model with 2 related first-order factors with one superordinate higher-order factor (model 3) and a bifactor model (model 4).

In general, fit indices were adequate for the four models tested (see Table 2). Taking into account that S-B chi-square differences between the models were not significant -and therefore all models fit equally well statistically- the simplest model was selected (unidimensional). Figure 1 shows the Final factor solution for the Spanish Dispositional Hope Scale.

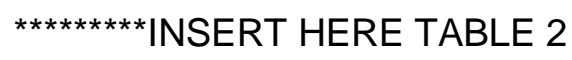

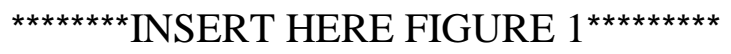




\subsection{Reliability: Internal consistency and test-retest}

Internal consistency coefficient (Cronbach's alpha) for the total scale was excellent (.89). Comparing our results with the original English study and to the Galiana et al. Spanish DHS study, Cronbach's alpha was higher (original version: from .74 to .84; Galiana et al version: .83). Additionally, the split-half reliability coefficient was acceptable (.87). Regarding time stability, test-retest analyses were conducted only with GP; the reliability value for the total score was .80 .

\subsection{Factorial Invariance across groups}

A forward multistage procedure was used to test factorial invariance of the Spanish DHS across GP and CP groups. An acceptable baseline model for both groups was found (see Table 3). Then, invariance of the factor loadings, intercepts and the residual variances across both groups were tested (see Table 4). Multi-sample analysis showed a strong factorial invariance of the scale, with invariant factorial loadings and partially invariant intercepts (free intercepts of items 6,8 and 9) (Model 2P).

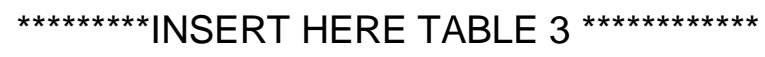

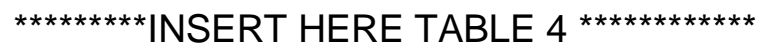

\subsection{Differences between clinical and non-clinical groups.}

Chi square and $\mathrm{T}$ tests were conducted to compare the sociodemographic and psychological characteristics of the two subsamples. Regarding sociodemographic characteristics, significant differences were found for sex and age. The $\mathrm{CP}$ group includes a smaller proportion of men 
$(3.3 \%$ vs $22 \%)\left(\mathrm{X}^{2}(1, \mathrm{~N}=290)=20.458, p<.001, \mathrm{~V}=0.27\right)$ than the $\mathrm{GP}$, and CPs are older than GPs (44.3 years vs 27.9 years old; $(\mathrm{t}(282)=-13.180, p<.001, \mathrm{~d}=-1.52)$. Moreover, significant differences were detected in marital status and educational level. Most of the GPs were single $(81.5 \%)$ and had a superior educational level (81\%), while a large percentage of CPs were married $(58.2 \%)\left(\mathrm{X}^{2}(3, \mathrm{~N}=290)=96.972, p<.001, \mathrm{~V}=0.58\right)$ and had a basic educational level $(46.4 \%)\left(\mathrm{X}^{2}(2, \mathrm{~N}=290)=108.674 . p<.001, \mathrm{~V}=0.71\right)$. In the case of the psychological variables, significant differences were found in quality of life $(\mathrm{t}(137)=10,517 ; p<.001, \mathrm{~d}=1.78)$, positive affect $(\mathrm{t}(145)=4,861 ; p<.001, \mathrm{~d}=0.82)$, and optimism levels $(\mathrm{t}(179)=5,533 ; p<.001, \mathrm{~d}=0.87)$. CPs obtained lower values than GPs on all these measures. In addition, CPs obtained significantly higher levels of depressive symptomatology $(\mathrm{t}(132)=-5,714 ; p<.001, \mathrm{~d}=-0.79)$.

Regarding hope scores, significant differences were found between both groups. GPs perceived themselves as more capable of creating routes to their desired goals, and they showed more goal-directed energy to initiate and continue the use of these routes, compared to the CP group $(\mathrm{X}=52.38, \mathrm{SD}=7.22$ vs $\mathrm{X}=45.07, \mathrm{SD}=9.96 ; \mathrm{t}(208.9)=6,897 ; p<.001, \mathrm{~d}=0.84)$.

Taking into account the differences in age, sex, marital status and educational level found between the two groups, these variables were included as covariables to control their influence. After this step, the differences between GPs and CPs on hope scores remained significant $(p<.001)$. However, when positive affect, quality of life, optimism and depressive symptoms were included as covariables, significant differences in hope scores between CPs and GPs became diluted (see table 5). Positive affect and depressive symptoms showed a significant effect on hope scores, and so the differences previously detected in total hope have to be attributed to these variables. 


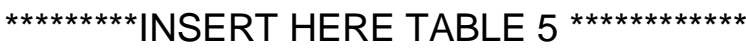

\subsection{Correlation analyses}

Correlation coefficients in GP are summarized in Table 6. General Hope scores were strongly associated with all measures in the expected direction (positive and significant relationship with optimism, quality of life and positive affect, and inversely correlated to depression, hopelessness and negative affect) For each correlation value, standard Z scores were calculated to compare them to the $\mathrm{CP}$ correlation scores.

${ }^{* * * * * \star * *}$ INSERT HERE TABLE $6^{* * * * * \star * * * * * *}$

Correlation coefficients in CP are summarized in Table 7. Results were similar to those obtained in the GP group but, although statistically significant, the correlation scores were lower than those obtained in the GP group.

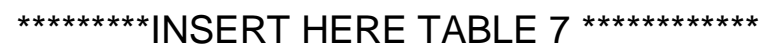

\section{Discussion}

The first aim of this paper was to evaluate the factorial structure of the Spanish version of the DHS in general and clinical Spanish populations. Our factorial findings are in line with the previous analysis of a Spanish DHS (Galiana et al., 2014), which proposed a one-factor solution. Taking into account this previous work and the present outcomes, it is possible to suggest that a "global" hope construct is a better approach for Spanish population, instead of a more 
differentiated one, as the model originally proposed by Snyder (two-factor structure with one higher-order factor). Furthermore, we demonstrated that the Spanish version of DHS has a strong factorial invariance between populations, so it is possible to support the premise that this unidimensional model of hope is applicable not only to general population but also for clinical population. It is necessary, however, to consider that three items were released when factorial invariance was tested (numbers 6,8 and 9), which indicates that both populations does not respond in the same manner to them. These items are: "I can think of many ways to get the things in life that are most important to me" (item 6, Snyder`s Pathways), "Even when others get discouraged, I know I can find a way to solve the problem" (item 8, Snyder`s Pathways) and "My past experiences have prepared me well for my future" (item 9, Snyder`s Agency). This highlights that although the "global" hope scores of both populations are comparables, these are populations with quite different characteristics, and therefore future studies should replicate these findings and explore the presence of bias in these particular items with bigger clinical and general samples.

Regarding internal consistency, high values were obtained and adequate time stability index was also observed, an important psychometric property for a dispositional measurement, and one not previously assessed with the Spanish DHS. Regarding criterion validity, significant correlations were found between the DHS and measures of depression, hopelessness, positive and negative affect, optimism, general self-efficacy and quality of life.

Differences were detected between CP and GP in their hope scores. Previous studies with chronic medical conditions (our most prevalent type of $\mathrm{CP}$ ) have described variations in hope related to illness symptoms (e.g., pain and fatigue in cancer patients), psychological distress (like depression) and personal resources, such as self-efficacy (Berendes et al., 2010; Venning et al., 
2007). In addition, dispositional hope has been found to behave differently from optimism (Affleck \& Tennen, 1996). The outcomes obtained in the present study suggest that the low hope scores detected in the $\mathrm{CP}$ were mainly associated with their low positive affect and high depressive symptoms, and not with their low optimism scores. This finding is in line with previous research and with the relevance of well-being and psychological distress in this population. Taking into account that the $\mathrm{CP}$ group included in this study was not only composed of medical conditions, it would be necessary to corroborate these findings in a homogeneous $\mathrm{CP}$ sample. Moreover, it would be relevant to continue to explore the variables that could help to maintain hope levels in chronic medical contexts, and to determine whether these variables are acting on "state" or "dispositional" hope levels.

Several limitations of the study should be considered. First, the greater proportion of women in our sample limits the generalization of the results. Second, the composition of the clinical group is not balanced, with medical conditions prevailing (fibromyalgia and cancer). Given the limited size of this group, it was not possible to analyze the data considering each diagnosis (medical and psychological conditions). Future studies with larger samples of clinical populations should compare these groups in terms of hope, self-efficacy and optimism levels, and corroborate the present results. Third, test-retest analyses were not conducted with clinical population, and therefore it is not possible to conclude about the stability of the scale in this population.

In spite of these limitations, the results obtained in the present study broaden the existing data about the Spanish DHS, and they support the use of this scale in both general and clinical Spanish populations, showing its usefulness not just for research but also for clinical purposes. 


\section{References}

Abdel-Khalek, A., \& Snyder, C. (2007). Correlates and predictors of an Arabic translation of the Snyder Hope Scale. The Journal of Positive Psychology, 2(4), 228-235.

Affleck, G. \& Tennen, H. (1996). Construing Benefits from Adversity: Adaptational Significance and Dispositional Underpinnings. Journal of Personality, 64(4), 899-922.

Aguilar, E., Hidalgo, M., Cano, R., López, J., Campillo, M. \& Hernández, J. (1995). Estudio prospectivo de la desesperanza en pacientes psicóticos de inicio: características psicométricas de la escala de desesperanza de Beck en este grupo. Anales de Psiquiatría, 2, 121-125.

Alarcon, G., Bowling, N. \& Khazon, S. (2013). Great expectations: A meta-analytic examination of optimism and hope. Personality and Individual Differences, 54, 821-827.

Babyak, M., Snyder, C. \& Yoshinobu, L. (1993). Psychometric properties of the Hope Scale: A confirmatory factor analysis. Journal of Research in Personality, 27(2), 154-169.

Beck, A. T., Steer, R. A., \& Brown, G. K. (1996). Manual for the beck depression inventory. The Psychological Corporation. San Antonio, TX.

Beck, A. T., Weissman, A., Lester, D., \& Trexler, L. (1974). The measurement of pessimism: the hopelessness scale. Journal of consulting and clinical psychology, 42(6), 861.

Berendes, D., Keefe, F., Somers, T., Kothadia, S., Porter, L. \& Cheavens, J. (2010). Hope in the Context of Lung Cancer: Relationships of Hope to Symptoms and Psychological Distress. Journal of Pain and Symptom Management, 40(2), 174-182.

Bosscher, R., Smit, J. \& Kempen, G. (1997). Algemene competentieverwachtingen bij ouderen: Een onderzoek naar de psychometrische kenmerken van de algemene competentieschaal. Nederlands Tijdschrift voor de Psychologie, 52(6), 239-248. 
Brouwer, D., Meijer, R., Weekers, A. \& Baneke, J. (2008). On the Dimensionality of the Dispositional Hope Scale. Psychological Assessment, 20(3), 310-315.

Chang, E. \& Banks, K. (2007). The Color and Texture of Hope: Some Preliminary Findings and Implications for Hope Theory and Counseling Among Diverse Racial/Ethnic Groups. Cultural Diversity and Ethnic Minority Psychology, 13(2), 94-103.

Chang, E. \& DeSimone, Sh. (2001). The influence of hope on appraisals, coping, and dysphoria: A test of hope theory. Journal of Social and Clinical Psychology, 20(2), 117-129.

Chen, C., Shen, H., \& Li, X. (2009). Reliability and validity of adult dispositional Hope Scale.

[Chinese]. Chinese Journal of Clinical Psychology, 17(1), 24-26. P

Creamer, M., O’Donnell, M., Carboon, I., Lewis, V., Densley, K., McFarlane, A., Silove, D. \& Bryant, R. (2009). Evaluation of the Dispositional Hope Scale in injury survivors. Journal of Research in Personality, 43, 613-617.

Feldman, D. \& Snyder, C. (2005). Hope and the Meaningful Life: Theoretical and Empirical Associations Between Goal-Directed Thinking and Life Meaning. Journal of Social and Clinical Psychology, 24(3), 401-421.

Galiana, L., Oliver, A., Sancho, P \& Tomas, J. (2014). Dimensionality and Validation of the Dispositional Hope Scale in a Spanish Sample. Social Indicators Research, 1-12.

Gana, K., Daigre, S. \& Ledrich, J. (2013). Psychometric Properties of the French Version of the Adult Dispositional Hope Scale. Assessment, 20(1), 114-118.

Hellman, Ch., Pittman, M. \& Munoz, R. (2013). The First Twenty Years of the Will and the Ways: An Examination of Score Reliability Distribution on Snyder's Dispositional Hope Scale. $J$ Happiness Stud, 14, 723-729. DOI 10.1007/s10902-012-9351-5 
Herrero, R., Espinoza, M., Molinari, G., Etchemendy, E., Garcia-Palacios, A., Botella, C. \& Baños, R.M. Psychometric properties of the General Self Efficacy-12 scale in Spanish: general and clinical population samples. Comprehensive Psychiatry, 55, 1738-1743.

Hu, L. T., \& Bentler, P. M. (1999). Cutoff criteria for fit indexes in covariance structure analysis: Conventional criteria versus new alternatives. Structural Equation Modeling: A Multidisciplinary Journal, 6(1), 1-55.

Irving, L., Snyder, C., Cheavens, J., Gravel, L., Hanke, J., Hilberg, P. \& Nelson, N. (2004). The Relationships Between Hope and Outcomes at the Pretreatment, Beginning, and Later Phases of Psychotherapy. Journal of Psychotherapy Integration, 14(4), 419-443.

Kato, T. \& Snyder, C. (2005). The relationship between hope and subjective well-being: Reliability and validity of the dispositional hope scale, Japanese version. Japanese Journal of Psychology,76(3), 227-234.

Kortte, K., Stevenson, J., Hosey, M., Castillo, R. \& Wegener, S. (2012). Hope Predicts Positive Functional Role Outcomes in Acute Rehabilitation Populations. Rehabilitation Psychology, $57(3), 248-255$.

Magaletta, P. \& Oliver, J. (1999). The Hope Construct, Will and Ways: Their Relations with Self-Efficacy, Optimism, and General Well-Being. Journal of Clinical Psychology, 55(5), 539551.

Marques, S., Lopez, S., Fontaine, A., Coimbra, S. \& Mitchell, J. (2014). Validation of a Portuguese Version of the Snyder Hope Scale in a Sample of High School Students. Journal of Psychoeducational Assessment, 1-6. 
Mezzich, J. E., Ruipérez, M. A., Pérez, C., Yoon, G., Liu, J., \& Mahmud, S. (2000). The Spanish version of the quality of life index: presentation and validation. The Journal of nervous and mental disease, 188(5), 301-305.

Moraitou, D., Kolovou, Ch., Papasozomenou, Ch. \& Paschoula, C. (2006). Hope and Adaptation to Old Age: Their Relationship with Individual-Demographic Factors. Social Indicators Research, 76, 71-93. Doi 10.1007/S11205-005-4857-4

Perczek, R., Carver, C. S., Price, A. A., \& Pozo-Kaderman, C. (2000). Coping, mood, and aspects of personality in Spanish translation and evidence of convergence with English versions. Journal of Personality Assessment, 74(1), 63-87.

Roesch, S. \& Vaughn, A. (2006). Evidence for the Factorial Validity of the Dispositional Hope Scale. Cross-Ethnic and Cross-Gender Measurement Equivalence. European Journal of Psychological Assessment, 22(2),78-84. DOI 10.1027/1015-5759.22.2.78

Sanz, J., Navarro, M. E., \& Vázquez, C. (2003). Adaptación española del Inventario para la depresión de Beck-II (BDI-II): 1. Propiedades psicométricas en estudiantes universitarios. Análisis y modificación de conducta, 29(124), 239-288.

Scheier, M. F., Carver, C. S., \& Bridges, M. W. (1994). Distinguishing optimism from neuroticism (and trait anxiety, self-mastery, and self-esteem): a reevaluation of the Life Orientation Test. Journal of personality and social psychology, 67(6), 1063.

Seisdedos, N. (1988). Cuestionario de ansiedad estado-rasgo. Adaptación española. Madrid: TEA.

Shehni-Yailagh, M., Kianpour Ghahfarkhi, F., Maktabi, G., Neasi, A. \& Samavi, A. (2012). Reliability and validity of the Hope Scale in the Iranian Students, J. Life Sci. Biomed, 2(4), 125128. 
Snyder, C., Harris, C., Anderson, J., Holleran, S., Irving, L., Sigmon, S., Yoshinobu, L., Gibb, J., Langelle, Ch. \& Harney, P. (1991). The Will and the Ways: Development and Validation of an Individual-Differences Measure of Hope. Journal of Personality and Social Psychology, $60(4), 570-585$.

Snyder, C., Lehman, K., Kluck, B. \& Monsson, Y. (2006). Hope for Rehabilitation and Vice Versa. Rehabilitation Psychology, 51(2), 89-112.

Snyder, C., Rand, K., King, E., Feldman, D. \& Woodward, J. (2002). "False” Hope. Journal of Clinical Psychology, 58(9), 1003-1022.

Spielberger, C. D., Gorsuch, R., \& Lushene, R. E. (1970). Manual for the state-trait inventory. Consulting Psychologists, Palo Alto, California.

Stanton, A., Danoff- burg, S. \& Huggins, M. (2002). The first year after breast cancer diagnosis: hope and coping strategies as predictors of adjustment. Psycho-Oncology, 11(2), 93-102.

Sun, Q., Ng, K. \& Wang, Ch. (2012). A Validation Study on a New Chinese Version of the Dispositional Hope Scale. Measurement and Evaluation in Counseling and Development, 45(2), $133-148$.

Venning, A., Eliott, J., Whitford, H. \& Honnor, J. (2007). The Impact of a Child's Chronic Illness on Hopeful Thinking in Children and Parents. Journal of Social and Clinical Psychology, $26(6), 708-727$.

Vernberg, D., Snyder, C. \& Schuh, M. (2005). Preliminary validation of a hope scale for a rare health condition using web-based methodology. Cognition \& Emotion, 19(4), 601-610.

Watson, D., Clark, L. A., \& Tellegen, A. (1988). Development and validation of brief measures of positive and negative affect: the PANAS scales. Journal of personality and social psychology, 54(6), 1063. 
Woodruff, S., \& Cashman, J. (1993). Task, Domain, and General Efficacy: A Reexamination of the Self-Efficacy Scale. Psychological Reports, 72(2), 423-432. 
Table 1. Demographic characteristics of general and clinical samples

\begin{tabular}{|c|c|c|c|c|}
\hline & & $\begin{array}{c}\text { Total } \\
\text { Sample }\end{array}$ & $\begin{array}{c}\text { General } \\
\text { Population }\end{array}$ & $\begin{array}{c}\text { Clinical } \\
\text { Population }\end{array}$ \\
\hline \multirow[t]{2}{*}{ Age } & & 34.6 & 27.93 & 44.30 \\
\hline & & (SD 13.05) & (SD 7.81) & (SD 13.07) \\
\hline \multirow[t]{4}{*}{ Sex } & Male & 41 & 37 & 4 \\
\hline & & $(14.1 \%)$ & $(22 \%)$ & $(3.3 \%)$ \\
\hline & Female & 249 & 131 & 118 \\
\hline & & $(85.9 \%)$ & $(78 \%)$ & $(96.7 \%)$ \\
\hline \multirow{6}{*}{$\begin{array}{c}\text { Educational } \\
\text { Level }\end{array}$} & Basic & 69 & 12 & 57 \\
\hline & & $(23.8 \%)$ & $(7.1 \%)$ & $46.4 \%)$ \\
\hline & Medium & 57 & 20 & 37 \\
\hline & & $(19.6 \%)$ & $(11.9 \%)$ & $(30.9 \%)$ \\
\hline & High & 164 & 136 & 28 \\
\hline & & $(56.5 \%)$ & $(81 \%)$ & $(22.7 \%)$ \\
\hline \multirow[t]{9}{*}{ Marital Status } & Single & 167 & 137 & 30 \\
\hline & & $(57.6 \%)$ & $(81.5 \%)$ & $(24.6 \%)$ \\
\hline & Married/ & 91 & 20 & 71 \\
\hline & Living with & $(31.4 \%)$ & $(11.9 \%)$ & $(58.2 \%)$ \\
\hline & partner & & & \\
\hline & Separated & 29 & 11 & 18 \\
\hline & & $(10 \%)$ & $(6.5 \%)$ & $(14.8 \%)$ \\
\hline & Widow & 3 & 0 & 3 \\
\hline & & $(1 \%)$ & $(0 \%)$ & $(2.5 \%)$ \\
\hline
\end{tabular}


Table 2. Goodness-of-Fit Indexes for the Models Comparison

$90 \%$ CI for

RMSEA

\begin{tabular}{lccccccccc} 
Model & SB- $\chi 2$ & $\mathrm{df}$ & $\mathrm{p}(\Delta \mathrm{SB}-\chi 2)$ & $\mathrm{CFI}$ & $\mathrm{TLI}$ & SRMR & RMSEA & LL & UL \\
\hline Unidimensional & 42.307 & 19 & & .957 & .933 & .036 & .065 & .039 & .091 \\
Two correlated Factors & 38.319 & 18 & 0.06 & .963 & .942 & .033 & .062 & .035 & .090 \\
Second Order Model & 36.191 & 17 & 0.24 & .965 & .942 & .033 & .062 & .034 & .091 \\
Bifactor Model & 27.979 & 13 & 0.07 & .972 & .941 & .030 & .063 & .030 & .095
\end{tabular}

Note: SB- $\chi 2$ = Satorra-Bentler chi-square fi statistic; $\mathrm{CFI}=$ comparative fit index; SRMR = standarized root mean squared residual; RMSEA = root mean square error of approcimation; $\mathrm{CI}=$ confidence interval; $\mathrm{LL}=$ lower limit; UL = upper limit.

$* 1 \mathrm{p}<.001 ; * 2 \mathrm{p}<.001$ 
Table 3. Goodness-of-Fit Indexes for the Baseline Model in Two Groups

$90 \%$ CI for

RMSEA

\begin{tabular}{lccccccc} 
Group & SB- $\chi^{2}$ & $d f$ & CFI & SRMR & RMSEA & LL & UL \\
\hline Clinical & $33.766^{* *}$ & 19 & .933 & .049 & .080 & .032 & .123 \\
General & $60.214^{* *}$ & 19 & .930 & .050 & .114 & .082 & .147
\end{tabular}

Note: $\chi^{2}=$ Chi-square fi statistic; CFI = comparative fit index; SRMR = standarized root mean squared residual; RMSEA = root mean square error of approximation; $\mathrm{CI}=$ confidence interval; $\mathrm{LL}=$ lower limit; $\mathrm{UL}=$ upper limit.

$* \mathrm{p}<.05 ; * * \mathrm{p}<.01$ 
Table 4. Testing for invariance of the Factor Model Across Two Groups

\begin{tabular}{lccccccc}
\hline Model & SB- $\chi 2$ & $d f$ & Comparison & $p$ & CFI & $\Delta$ CFI & RMSEA \\
\hline M0 & 91.922 & 38 & & & .929 & & .099 \\
M1 & 104.200 & 45 & M1-M0 & .10 & .922 & -.007 & .069 \\
M2 & 132.573 & 52 & M2-M1 & $<.001$ & .894 & -.028 & .103 \\
M2P & 110.887 & 49 & M2P-M1 & .20 & .919 & .003 & .093 \\
M3 & 298.848 & 57 & M3-M2P & $<.001$ & .683 & -.236 & .171 \\
\hline
\end{tabular}

Note: $\chi 2=$ Chi-square fi statistic; $\mathrm{CFI}=$ comparative fit index; RMSEA = root mean square error of approcimation; $\mathrm{M} 0=$ baseline model (no invariance imposed); $\mathrm{M} 1$ = invariant factor loadings; M2 = invariant factor loadings and invariant intercepts $\mathrm{M} 2 \mathrm{P}=$ invariant factor loadings and partially invariant intercepts (free intercepts of items 6, 8 and 9); M3 = invariant factor loadings, partially invariant intercepts and invariant residual variances.

a. $\triangle \mathrm{CFI}<-.01$ (signal lack of invariance).

$* \mathrm{p}<.05 ; * * \mathrm{p}<.01$ 
Table 5: MANCOVA analysis

\begin{tabular}{llcc}
\hline & & F & p \\
\hline Positive Affect & Hope & 4.435 & $.038^{*}$ \\
Quality of Life & Hope & 1.521 & .220 \\
Optimism & Hope & .028 & .867 \\
Depressive Symptoms & Hope & 5.900 & $.017^{*}$ \\
Population & Hope & .596 & .442 \\
& & & \\
\hline
\end{tabular}


Table 6. Relationship between Hope levels and quality of life, optimism, positive/negative affect, hopelessness and depression in Spanish GP.

\begin{tabular}{ccccccc}
\hline Spanish & LOT-R & PANAS & PANAS & QLI-Sp & BDI & BHS \\
Hope & \multicolumn{7}{c}{ NA } & PA & & & \\
& $(\mathrm{Z})$ & $(\mathrm{Z})$ & $(\mathrm{Z})$ & $(\mathrm{Z})$ & $(\mathrm{Z})$ & $(\mathrm{Z})$ \\
\hline & $.650^{* *}$ & $-.617^{* *}$ & $.655^{* *}$ & $.694^{* *}$ & $-.614^{* *}$ & $-.770^{* *}$ \\
& $(0.78)$ & $(0.73)$ & $(0.79)$ & $(0.85)$ & $(0.71)$ & $(1.02)$ \\
\hline
\end{tabular}


Table 7. Relationship between Hope levels and quality of life, optimism, positive/negative affect, depression and general self-efficacy in CP.

\begin{tabular}{|c|c|c|c|c|c|c|}
\hline Spanish & $L O T-R$ & PANAS & PANAS & $Q L I-S p$ & $B D I$ & GSES-12 \\
\hline \multirow[t]{2}{*}{ Hope } & & $N A$ & $P A$ & & & \\
\hline & $(Z)$ & $(Z)$ & (Z) & $\left(Z^{\prime}\right)$ & $\left(Z^{\prime}\right)$ & $\left(Z^{\prime}\right)$ \\
\hline \multirow[t]{2}{*}{ Total } & $.298 * *$ & $-.245^{*}$ & $.459 * *$ & $.503 * *$ & $-.513 * *$ & $.531 * *$ \\
\hline & $(0.31)$ & $(0.26)$ & (0.50) & $(0.55)$ & $(0.56)$ & $(0.59)$ \\
\hline
\end{tabular}


Figure 1. Final factor solution for the Spanish Dispositional Hope Scale

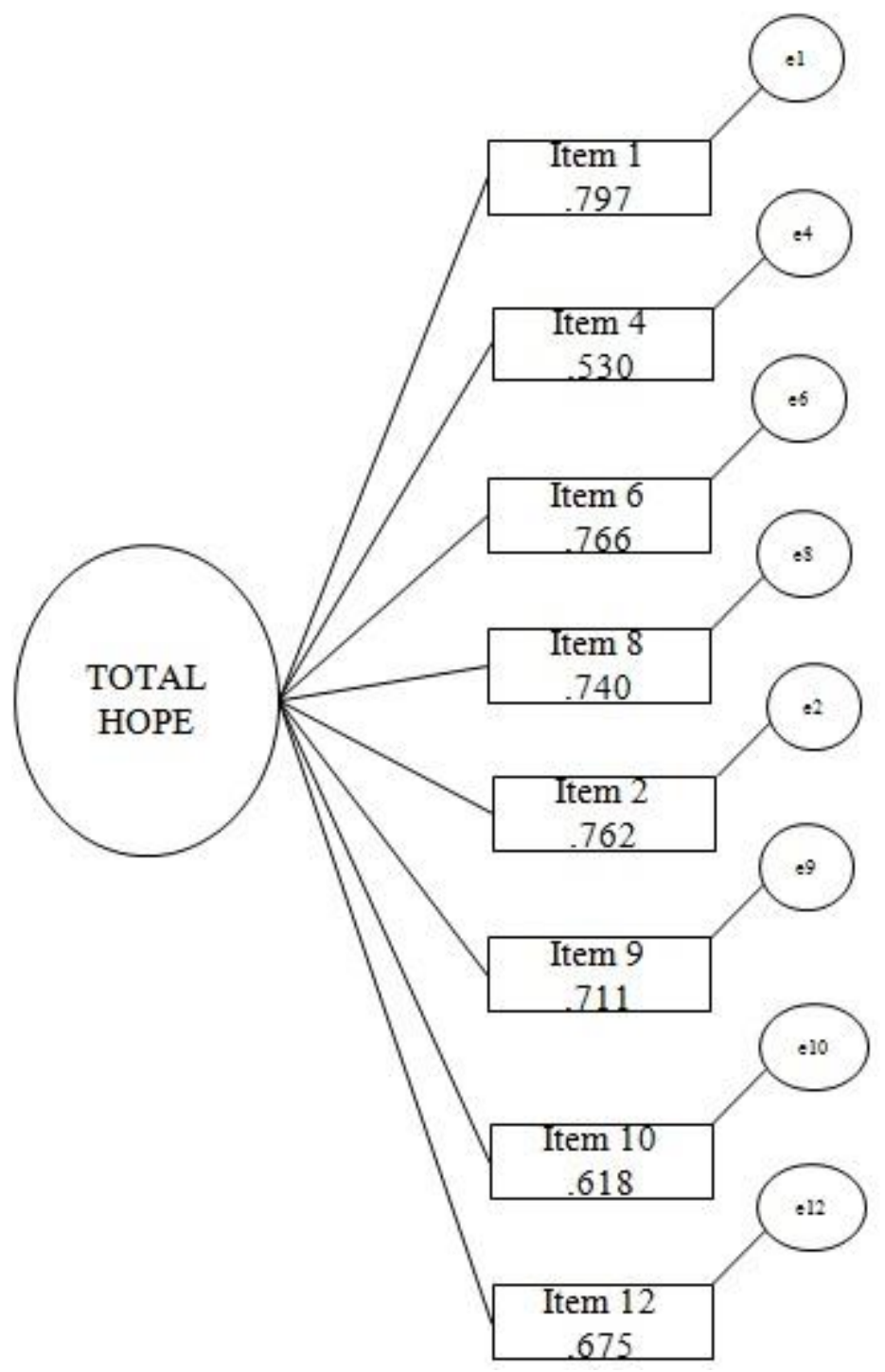

